\title{
II Reunião de Diretores e Chefes de Pessoal do Serviço Públıco Civil da União
}

(27, 28 e 29 de outubro de 1969)

\section{DEFINIÇÃO DE OBJETIVOS E FUNCIONAMENTO}

N A I Reunião realizada em Brasilia, de 6 a 8 de agôsto de 1969 , foram esclarecidos os fundamentos e as linhas gerais da filosofia da reforma da administração de pessoal civil do Serviço Público Federal. A permuta de idéias e informações então havida permitiu que o DASP e os Órgãos de Pessoal da Administração direta e indireta estabelecessem uma base comum de enten. dimento, graças à qual é possivel cuidar-se, doravante, de problemas determinados.

Com êsse objetivo é que o DASP convocou os Dirigentes dos Órgãos centrais de Pessoal dos Ministérios e das entidades de maior porte da administração indireta para, acompanhados de seus assessôres especializados, comparecerem à II REUNIÃo, que se realizou em Brasília, nos dias 27, 28 e 29 de outubro de 1969.

Constituiu objeto dos trabalhos nesse encontro a elaboração de recomendações objetivas, visando à adoção de soluções mais apropriadas para os problemas relativos aos seguintes Temas:

1 - Sistema de Pessoal

2 - Subsistema de Cadastro

3 - Treinamento

4 - Recrutamento e Seleção

O exame dos problemas suscitados em relação a cada um dos Temas indicados coube a uma Comissão que, ao final dos debates, apresentou Recomendações pertinentes.

As Recomendaçõ̀es fcram apresentadas com objetividade e concisão. Foi dispensada a justificação das soluções propostas, desde que refletissem a opinião da maioria dos membros da Comissão.

Com o propósito de motivar os debates sôbre cada um dos Temas, foram elaborados documentos contendo considerações e indagações relacionadas com a problemática respectiva. 
Cada Dirigente de Órgão de Pessoal convocado compareceu à II REUNIÃo acompanhado de assessôres qualificados para comporem Comissões diversas.

Sob a supervisão direta do Coordenador da Reunião, funcionou uma Secretaria Executiva, subdividida em setores especificos correspondentes às Comissões.

As Sessões da Reunião obedeceram ao seguinte calendário: Dia 27 de outubro

10,00 horas - Abertura da Reunião, no Auditório ( $5^{\circ}$ andar) sob a presidência do Diretor-Geral do DASP — Designação dos membros de cada Comissão.

14,00 às 19,00 horas - Início dos trabalhos das Comissões.

Dia 28 de outubro

9,00 às 12,00 horas e 14 às 19,00 horas - Prosseguimento dos trabalhos.

Dia 29 de outubro

9,00 às 12,00 horas - Elaboração das Recomendações.

14,00 horas - Encerramento da Reunião, no Auditório, com a apresentação ao plenário das Recomendações oferecidas pelas Comissões.

\section{ANEXO I}

TEMA:

\section{SISTEMA DE PESSOAL}

\section{MOTIVAÇÃO DOS TRABALHOS}

$\left.1^{\circ}\right)$ Deve o sistema de pessoal ser único e abranger a Administração Direta, as Autarquias e os setores da Administração Indireta que recebam transferência de recursos da União?

$\left.2^{\circ}\right)$ Deve o sistema de pessoal ser dividido em dois setores rigorosamente definidos: a) um órgão central, com funções exclusivas de planejamento, orientação e contrôle; b) um conjunto de órgãos setoriais (um em cada Ministério ou órgão autônomo), ao qual seriam atribuídas tôdas as funções executivas da administração de pessoal?

3) Para melhor funcionamento do sistema, deveria haver órgãos regionais de pessoal - aos quais ficassem subordinadas, administrativamente, as unidades e subunidades dos órgãos setoriais de cúpula? Em caso afirmativo, poder-se-ia adotar na criação dos órgãos regionais o mesmo critério de divisão do País em regióes, adotado pelo IBGE? Como seriam estabelecidas a articulação 
e coordenação das atividades entre os Órgãos Setoriais de cúpula e os Órgãos Regionais, e entre êstes e as Ûnidades e Subunidades?

49). Deve ser mantida a fórmula atual de subordinar $\sim$ se o Órgão Central de Pessoal diretamente à Presidência da República, e de limitar-se sua supervisão pelo Ministro do Planejamento e Coordenação Geral aos assuntos referentes à reforma administrativa? E quanto aos Órgãos setoriais: julga válida a idéia de subordiná-los diretamente aos respectivos Ministros de Estado?

5:) Deve o Órgão Central do Sistema ter uma participação necessária e decisiva na escolha dos dirigentes dos órgãos setoriais e êstes, por sua vez, na dos chefes das unidades e subunidades de sua jurisdição?

60) Num sistema de pessoal a unidade de orientação é indispensável e, por isso, os órgãos setoriais devem ser tèsnicamente subordinados ao Órgão Central, competindo a êste expedir, obrigatòriamente, os regulamentos, normas e diretrizes necessários ao entendimento e execução uniforme da politica de pessoal?

$\left.7^{\circ}\right)$ Ainda com o propósito de preservar a unidade de orientação técnica do sístema, deveria o Órgão Central constituir uma instância para decidir em definitivo, na esfera administrativa, os recursos das decisões dos órgãos setoriais?

ANEXO 2

TEMA

\section{SUBSISTEMA DE CADASTRO}

\section{MOTIVAÇÃO DOS TRABALHOS}

O objetivo principal da instituição do Cadastro Permanente da Administração Federal foi o de permitir o conhecimento globalizado dos servidores civis, quer da administração direta, como das autarquias. Inclui, também, órgãos da administração indireta que recebam transferência de recursos orçamentários da União.

Visava-se a conseguir, inicialmente, dados numéricos, nominais e outros elementos que fôssem necessários à formulação ou revisão de uma política de pessoal. Para tanto, foi baixado o Decreto $n^{\circ} 64.564$, de 22 de maio de 1969 , o qual prevê, igualmente, a instituição de um subsistema que mantenha atualizado e sobretudo atuante o cadastro instituído.

Adotou-se, de logo, a diretriz de utilizar-se no sistema a computação eletrônica, a fim de que se aproveitasse a velocidade e o volume de informações que só êsse método pode oferecer. 
E mais, estamos atingindo uma fase em que, com quase certeza, o multiprocessamento, isto é, a execução de duas ou mais tarefas simultâneamente, terá de ser utilizado, a fim de aumentar a produtividade em relação ao tempo de uso da máquina e, de certa forma, evitar a duplicidade de tarefas ou de registros, onde não fôr essencialmente necessário.

Por isso, entendemos que se deva fixar, de logo, a estrutura do subsistema que se encarregará dessas tarefas.

A eficiência e compatibilidade de qualquer política de pessoal em emprêsas de grande envergadura (e qual a emprêsa maior do que o Estado?) depende, preponderantemente, da existência de contrôles e assentamentos de elementos básicos da vida funcional de seus empregados e de fatos ou atos a ela ligados.

Seria absurdo não aproveitar-se, nessa atividade, as vantagens oferecidas pelos computadores.

Conquanto tenha o nome de cadastro, na realidade o que se deve instituir é um registro integrado e multirrelacionado dos elementos essenciais ao exercício de tôdas as funções da administração de pessoal.

Para tanto, torna-se necessário definir e estabelecer:
A) a estrutura do subsistema;
B) a comunicação ou intercomunicação entre as diversas peças do subsistema;
C) contrôle dos atos;
D) a instrumentação a ser utilizada;
E) elementos ou dados a serem fornecidos.

\section{A - ESTRUTURA}

1) Coordenação Central do Subsistema de Cadastro diretamente subordinada ao Diretor-Geral do DASP;

2) Coordenação Setorial de Cadastro diretamente subordinada à Divisão de Pessoal do Ministério ou de órgão diretamente subordinado ao Presidente da República;

3) Coordenação Seccional de Cadastro diretamente subordinada ao Órgão de Pessoal de: 1) órgão de administração indireta que receba transfe-
rência de recursos orçamentários da União;

2) autarquia;

3) órgão autônomo integrante de Ministério ou que possua quadro próprio de pessoal.

4) Órgão de processamento de dados;

5) Tôda repartição que tiver mais de 500 servidores possuirá um agente de cadastro diretamente entrosado com o respectivo órgão. 


\section{B) COMUNICAÇスO}

1) O órgão central expedirá instruções gerais sôbre a forma e conteúdo dos Cadastros Central e Setoriais, que as retransmitirão aos Cadastros Seccionais;

2) os órgãos setoriais deverão comunicar ao órgão central a ocorrência de dificuldades na execução das instruções, diretamente;

3) os órgãos seccionais procederão da mesma forma indicada no item anterior, comunicando-se com os respectivos órgãos regionais;

4) os órgãos setoriais e seccionais enviarão diretamente ao órgão de processamento de dados os elementos a serem computados. Esste fará o multiprocessamento e enviará o resultado aos órgãos competentes.

\section{C - CONTRÔLE DOS ATOS}

Todos os atos relativos a pessoal serão publicados nos respectivos boletins e a autoridade que o expedir enviará uma cópia ao órgão de cadastro.

O órgão central procéderá a auditagens periódicas acíclicas nos órgãos regionais e seccionais. Os órgãos regionais procederão da mesma forma em relação aos órgãos seccionais.

\section{D - INSTRUMENTAÇAO A SER UTILIZADA}

De preferência serão utilizados cartões a serem fornecidos pelo órgão de processamento, acompanhados de listagens periódicas que globalizem os dados conjunturais.

\section{E - ELEMENTOS OU DADOS A SEREM FORNECIDOS}

1 - Dados constantes da $1^{\text {a }}$ fase (atualização)

2 - Nome

3 - Matrícula (IPASE - INPS)

4 - Filiação

5 - Data do nascimento

6 - Nacionalidade e naturalidade

7 - Número de dependentes, idade, sexo e grau de parentesco

8 - Estado Civil

9 - Cargos ou emprêgo

10 - Nivel ou salário

11 - Forma de provimento (diversas formas)

12 - Data da posse e ou exercício

13 - Tempo de Serviço:

a) classe

b) ministério ou órgão 

c) serviço público federal
d) serviço público em geral
14 - Dados para promoção
15 - Dados para acesso
16 - Vacância (diversas formas)
17 - Readaptação
18 - Penalidades
19 - Elogios
20 - Lotações (órgão onde presta serviços)
21 - Comissões
22 - Nível educacional
23 - Enderêço
24 - Gratificações e vantagens.

\section{ANEXO 3}

TEMA:

\section{TREINAMENTO}

\section{MOTIVAÇÃO DOS TRABALHOS}

Sob a forma de questionário, estão a seguir destacados diversos aspectos que devem merecer imediata consideração em tema de Treinamento de Pessoal.

$\left.1^{\circ}\right)$ Tendo em vista que a Reforma Administrativa dispensa ao Treinamento, como processo de mudança de atitudes, grande ênfase,

a) na área de trabalho de cada Órgão de Pessoal representado na Reunião têm sido realizados cursos sistemàticamente? De que tipo são os cursos? Cursos extraordinários, avulsos, simpósios ou conferências?

b) Existe, no Ministério ou Autarquia a que pertence Orgão de Pessoal representado, uma Unidade de Treinamento? Que relações tem mantido essa Unidade com os Órgãos de Treinamento do DASP? Deve essa Unidade de Treinamento integrar o Órgão de Pessoal do Ministério ou Entidade? Conta o Ministério ou Entidade com servidores preparados para ministrarem e administrarem o treinamento? Dispóe de recursos suficientes para o mesmo fim? Qual a participação que devem ter as Unidades de Treinamento na formulação da politica geral de treinamento da Administração Federal?

2.) Tendo em vista que, ressalvados os definidos em ato do Poder Executivo como de livre escolha do Presidente da República, o provimento dos cargos em comissão como das funções gratificadas - deverá vincular-se a 
especialização ou aperfeiçoamento do servidor em curso, apropriado (Art. 101, II, do Decreto-lei $\mathrm{n}^{\circ}$ 200, de 1967).

a) quais os cargos em comissão que devem ser providos pelo critério de livre escolha do Presidente da República? e

b) como devem ser caracterizados os cargos de «direção intermediária» e de «direção superior»?

3.) Tendo em vista que a Reforma Administrativa (Art. 121) atribui ao Centro de Aperfeiçoamento um conjunto de medidas relacionadas com o «assessoramento superior da Administração Civil»;

a) o que deve entender-se por Assessoramento Superior?

b) como deverá fazer-se o recrutamento dos que devam prestar êsse Assessoramento?

c) que critério de seleção deverá ser aplicado para o mesmo fim?

d) - Centro de Aperfeiçoamento deve cadastrar os candidatos ao provimento dos cargos corresponden tes ao Assessoramento Superior?

e) deve caber ao Centro de Aperfeiçoamento a indicação ou apenas a homologação da indicação de candidatos aos cargos de Assessoramento Superior?

f) o que deve entender-se por Assessoramento especializado? Por função de supervisão e por função especializada?

g) como distinguir a função de supervisão da simples função de chefia?

h) o treinamento para o Assessoramento Superior deve ser centralizado ou descentralizado?

i) como fazer o acompanhamento (avaliação de desempenho) do Assessoramento Superior?

j) em cada Ministério, quais os cargos que devem constituir o Assessoramento Superior da Administração Civil?

$\left.4^{\circ}\right)$ Tendo em vista que a política de treinamento a ser adotada pelo Govêrno há de basear-se em necessidades reais, quais Ministérios já procederam a levantamento das suas necessidades nessa matéria? Em que áreas?

5\%) Tendo em vista que o esclarecimento, através de treinamento, de aspectos psicossociais e tecnológicos da administração pública, como um complemento aos programas de treinamento específico, tem sido considerado como importante fator no desenvolvimento do pessoal,

a) De que forma se poderá imprimir ao serviço público uma nova orientação através do treinamento? 
b) O Chefe deve ser fator de ação educativa, ajustando e integrando o comportamento de seus servidores? Como se exerce essa ação?

c) como deve ser encarado um programa de treinamento através do qual as decisões resultassem de uma ação conjugada de chefes e subordinados? Isso importaria no comprometimento da autoridade?

d) $O$ que deve entender-se por treinamento em serviço e fora dêle?

e) Qual o tipo mais adequado de treinamento, tendo em vista as realidades presentes: Treinamento «tradicional»? Treinamento por correspondência? Treinamento prático (simulação operacional de situação real)? Treinamento misto (tradicional e prático)?

6.) Como sensibilizar os chefes e conscientizá-los da necessidade de se submeterem ao treinamento?

$7^{\circ}$ ) Como deve ser encarado o treinamento por entidades especializadas, públicas ou privadas, através de têrmos de cooperação, acôrdos, convênios e contratos?

$8^{\circ}$ ) Como provocar através do treinamento a modificação dos hábitos, atitudes e mentalidades dos servidores?

$\left.9^{\circ}\right)$ O treinamento é, por sí só, bastante para modificar a estrutura da organização burocrática?

10:) Como deve ser encarada a utilização de exames psicológicos para verificação de condições para o exercício de Chefias?

$11^{\circ}$ ) Como deve ser encarada a realização de um treinamento que objetive o reajustamento do servidor ao trabalho, considerando-se: a) o nivel mental geral; b) as aptidões especificas; c) as necessidades do serviço, na própria repartição ou em outra qualquer?

12.) A quem deverá caber o treinamento de iniciação? Deverá éle substituir o estágio probatório?

13:) Como deve ser encarada a aplicação de tecnologia aós processos de treinamento, através de televisão em circuitos fechados, de rádio e de filmes?

14ํ) Que medidas deve a Administração adotar com vistas a evitar o êxodo dos seus servidores qualificados?

$15^{\circ}$ ) Quais as formas de incentivos, além da simples remuneração, que poderiam ser atribuidas aos servidores em razão do seu indice de produtividade?

16.) Como deve ser encarada a realização de constantes programas de treinamento para racionalizar os processos tradicionais de comunicação administrativa: a) pela adoção de comunicação informal? b) pela simplificação da redação oficial? 


\title{
ANEXO 4
}

\section{TEMA:}

\section{ORGANIZAÇAO DO RECRUTAMENTO E DA SELEÇAO DE PESSOAL NA ADMINISTRAÇÃO DIRETA E NAS AUTARQUIAS}

\author{
MOTIVAÇÃO DOS TRABALHOS \\ QUESITO 1
}

A Divisão de Seleção e Aperfeiçoamento submete a exame dos Diretores e Chefes de Pessoal o anexo projeto de Norma Complementar esclarecedora das prescrições contidas no Decretolei $n^{9} 797 / 69$. A referida Norma satisfaz nos têrmos em que está vazada ou necessita maiores detalhamentos? Haveria necessidade de conceituar-se o que seja autarquia de maior porte? No caso, qual a melhor conceituação a sugerir-se?

\section{QUESITO 2}

Quais as Instruções Básicas de Orientação que a Divisão de Pessoal dos Ministérios e as unidades equivalentes das Autarquias (órgãos de gestão executiva) consideram que devam receber Prioritàriamente da Divisão de Seleção e Áperfeiçoamento do DASP (órgão de gestão normativa)?

\section{QUESITO 3}

A Seleção de pessoal no Serviço Público deve continuar a ser feita (a) medindo-se e aplicando-se conhecimentos especificos referentes ao cargo a ser provido ou (b) pela só mensuração de conhecimentos gerais, submetendo-se o selecionado, depois do ingresso, a treinamento específico abrangente dos conhecimentos requeridos pelas atividades do cargo que se tem em vista preencher?

\section{QUESITO 4}

Não obstante a inclinação dos brasileiros pelos cargos públicos, haverá ainda necessidade de acionar-se uma bem definida política de recrutamento positivo, visando-se ao provimento dos cargos públicos?

Essa política, se necessária, (a) deverá atingir todos os cargos públicos ou (b) deverá atingir, apenas, os cargos técnicos e/ou cientificos?

\section{QUESITO 5}

Os órgãos de pessoal, em tese, preferem assistência normativa (a) sôbre o que fazer, (b) sôbre o como fazer ou (c) simultâneamente sôbre o que fazer e sôbre o como fazer? 


\section{QUESITO 6}

A par dos tradicionais concursos de provas ou de provas de titulos, justificar-se-ia a introdução, para certas carreiras, de outras formas de aferição de conhecimento com inscrição pública e competitiva, como (a) entrevistas dirigidas, (b) exames curriculares e/ou (c) aproveitamento de candidatos (Obedecida a ordem de classificação) através de cursos prévios de treinamento?

\section{QUESITO 7}

Deve-se continuar a dar vista das provas aos candidatos? Os órgãos de Pessoal teriam condições para dar vista de prova a todos os candidatos, em tôdas as localidades onde forem realizados os concursos? Caso não se desse essa vista, seria conveniente fornecer-se aos candidatos o Padrão de Correção para lhes possibilitar a possivel fundamentação do recurso preconizada no art. 3* do Decreto-lei n? $797 / 69$ ?

\section{QUESITO 8}

Deverão os concursos continuar com o prazo de validade limitado a 2 anos? Esse prazo continuaria a ser prorrogável, considerada, em cada caso, a conveniência administrativa?

\section{REGULAMENTO}

Art. 1: O recrutamento e a seleção de pessoal civil, em tôdas as suas fases, serão executados pelos órgãos de pessoal dos Ministérios e das Autarquias de maior porte, nos têrmos dêste Regulamento.

Art. 2. O processo seletivo compreende as seguintes fases:

a) recrutamento;

b) inscrição;

c) realização de provas, compreendendo o planejamento, aplicação e desidentificação;

d) correção, compreendendo também a identificação, vistà e revisão;

e) homologação dos resultados.

Art. 3? Aos órgãos de pessoal mencionados no art. 1\% caberá:

I - solicitar ao DASP autorização para iniciar qualquer processo seletivo, instruindo o pedido com informações sôbre quantidade de cargos ou empregos vagos, suas denominações e o nome da repartição e lugar onde o provimento se faz necessário; 
II - uma vez concedida a autorização, executar as fases mencionadas no art. $2^{\circ}$, adotando as Normas de Procedimento baixadas pela DSA do DASP;

III - remeter à DSA, tão logo estejam terminados os trabalhos de cada uma das fases, um pequeno relatório, que será objeto de padronização pela DSA;

IV - fornecer à DSA, após a conclusão do processo seletivo, os elementos que permitam a atualização do cadastro de candidatos, de acôrdo com as normas que forem estabelecidas;

Art. 4? Ao DASP, por intermédio da Divisão de Seleção e Aperfeiçoamento, caberá:

I - conceder, se não existirem nos seus registros candidatos habilitados em número suficiente, autorização para o início-do processo seletivo;

II - dar orientação normativa, supervisionar tècnicamente, coordenar e controlar as atividades relacionadas com processo seletivo, baixando, para tanto, Normas de Procedimento;

III - zelar pela integral observância das leis, regulamentos e normas que dispõem sôbre recrutamento e seleção de pessoal civil para a Administração Direta e para as Autarquias;

IV - intervir em qualquer fase do processo de seleção, inicialmente com o propósito assistencial e corretivo, caso seja verificada a inobservância das leis, regulamentos e normas que lhe digam respeito;

$\mathrm{V}$ - manter atualizado um cadastro de candidatos habilitados;

VI - indicar os candidatos para nomeação ou admissão.

Art. 5\% Abertas as inscrições, o órgão executor da seleção deverá conclui-la e homologar os seus resultados no prazo máximo improrrogável de 12 (doze) meses.

Parágrafo único. Os resultados não poderão ser homologados enquanto houver recurso administrativo carente de decisão.

Art. $6^{\circ}$ Os concorrentes a processo seletivo sòmente poderão apresentar um pedido de revisão fundamentado, relativamente ao resultado de cada prova, indicando, com precisão, as questões e os pontos a serem objeto de revisão, sob pena de indeferimento in limine. $\mathrm{O}$ pedido deve ser endereçado ao dirigente do órgão de pessoal que está executando a seleção, no prazo de 10 (dez) dias contados a partir da vista da prova. 


\section{NORMA DE PROCEDIMENTO N: 2/69}

Os Órgãos de Pessoal dos Ministérios e das Autarquias de maior porte depois de autorizados pelo DASP, nos têrmos do $\left\{2^{\circ}\right.$, do Decreto-lei $n^{9} 797$, de $27 / 08 / 69$, ao iniciar o processo seletivo para o provimento de cargos deverão obedecer a seguinte norma de procedimento, de acôrdo com as diversas fases do processamento de um concurso.

\section{1 ${ }^{\text {a }}$ FASE - RECRUTAMENTO}

É o processo de atrair com acêrto os melhores candidatos para cada cargo oferecido. O Recrutamento deve lançar mão de todos os meios de divulgação, não só pela imprensa escrita, falada e até televisionada, mas também de anúncios nas associações de classes, escolas, universidades, nos boletins internos da repartição, nas revistas técnicas, impressos fixados em locais de passagem etc. Devem figurar como conteúdo dos anúncios a descrição do cargo (atribuições sintéticas dos ocupantes, exemplos de tarefas, características especiais do cargo, linha de promoção e acesso) e vencimento total de vagas a serem preenchidas, informações breves sôbre as provas e orientação de quando, como e onde fazer a inscrição.

\section{$2^{a}$ FASE - INSCRIÇÕES}

As datas de abertura e de encerramento das inscrições deverão ser amplamente anunciados pelos meios normais de divulgação, inclusive na imprensa oficial. Dessa divulgação também deverão constar.

a) o local onde serão recebidos os pedidos de inscrição;

b) as exigências legais;

c) os limites de idade;

d) total de vagas que se pretende preencher;

e) nível do cargo.

O pedido de inscrição deverá constar do preenchimento de fichas fornecidas aos candidatos no local da inscrição, sendo-lhes, na ocasião, fornecida cópia do programa do concurso.

\section{$3^{\text {a }}$ FASE - REALIZAÇÃO DAS PROVAS}

Verificada a existência de candidatos inscritos, deverá ser providenciada a constituição de uma Banca Examinadora que, observando rigorosamente o programa distribuído aos candidatos, 
elaborará as questões de prova escrita ou planejará o roteiro da execução de trabalhos práticos e de argüição de prova prático-oral. Em seguida, serão confeccionados os folhetos que deverão ser colocados em envelopes invioláveis e que só serão abertos nos dias de provas e na presença dos candidatos.

Com base no número de candidatos inscritos, deverá ser escolhido o local ou locais de realização das provas, que serão divul gados, assim como o dia e hora, por meio de aviso público ou mediante têrmo de ciência. Ainda com base no total de inscritos, deverá ser providenciada a convocação dos colaboradores que deverão executar e fiscalizar as provas, levando-se em conta que, em média, deverá haver dois fiscais para cada sala de vinte candidatos.

Terminados os trabalhos de realização das provas, observarse-á, para perfeita segurança de isenção no julgamento, a desidentificação dos folhetos, isto é, os talões de identificação que acompanham os folhetos serão destacados logo após a conclusão de cada prova e deverão ficar em invólucros sob a responsabilidade do órgão de pessoal até o término do respectivo julgamento e, em seguida, os folhetos encaminhados aos examinadores para correção.

\section{$4^{n}$ FASE - CORREÇÃO}

A Banca Examinadora deverá estabelecer um critério de correção que será aplicado igualmente a tôdas as provas. Corrigidas as provas, deverá ser providenciada a identificação das mesmas pùblicamente, em dia, hora e local marcado prèviamente em edital publicado na imprensa oficial, pelos meios comuns de divulgação ou mediante têrmo de ciência submetido à assinatura dos interessados. Ao candidato deve ser permitido ter vista das provas que prestou, ocasião em que poderá fazer as anotações que desejar, inclusive, para o caso em que julgar necessário apresentar pedido de revisão (art. 3, do Decreto-lei n 797/69).

\section{5: FASE - RESULTADO FINAL E HOMOLOGAÇÃO}

Os resultados finais dos concursos deverão ser publicados, obedecendo-se à ordem decrescente do total de pontos obtidos. Deverão ser publicados; sòmente, os resultados relativos aos candidatos habilitados.

O concurso deverá ser homologado no prazo máximo de um ano a contar da abertura das inscrições $\left(\S 9^{\circ}\right.$, do art. $1^{\circ}$, da Lei $\left.\mathrm{n}^{\circ} 1.711 / 52\right)$.

O candidato habilitado em concurso deverá receber um certificado, que será expedido pelo órgão de pessoal. 


\section{DECRETO-LEI № 797, DE 27 DE AGÔSTO DE 1969}

Dispõe sôbre a forma de Recrutamento e Seleção do Pessoal Civil para a Administração Direta e para as Autarquias, e dá outras providências.

O Presidente da República, usando das atribuições que the confere o art. $2^{\circ}$ do Ato Institucional $\mathrm{n}^{0} 5$, de 13 de dezembro de 1969, decreta:

Art. 1? O recrutamento e a seleção de pessoal civil, em tôdas as suas fases, passam a ser executados pelos órgãos de Pessoal dos Ministérios e das Autarquias de maior porte a juizo do Poder Executivo, observado o disposto neste Decreto-lei.

Art. $2^{\circ}$ Antes de iniciar qualquer processo seletivo, o Órgão de Pessoal interessado deverá solicitar autorização ao Departamento Administrativo do Pessoal Civil (DASP), instruindo o pedido com informações sôbre a quantidade de cargos ou empregos vagos, suas denominações e o nome da repartição e lugar onde o provimento se faz necessário.

$\S 1^{\text {Q }}$ A autorização será concedida se não existirem, nos registros do DASP, candidatos habilitados em concurso ainda válido para os cargos ou empregos indicados, em número suficiente.

§ 2. O candidato habilitado em concurso sob jurisdição do DASP poderá ser, com a anuência do interessado, indistintamente indicado para admissão na Administração Direta ou em Autarquia, caso não haja remanescente do concurso especifico para determinado órgão ou entidade.

§ 32 Quando se tratar de recrutar e selecionar pessoal para prover cargos ou preencher funções ou empregos existentes no seu próprio quadro ou tabela, o DASP poderá atuar como órgão operacional, desincumbindo-se diretamente do processo seletivo.

Art. $3^{\circ}$ Os concorrentes a processo seletivo sòmente poderão apresentar um pedido de revisão fundamentado, relativamente ao resultado de cada uma das provas do concurso, consoante estabelecerem as respectivas Instruções, não cabendo outros recursos na órbita administrativa.

Art. 4: Prescreve em 1 (um) ano, a contar da data em que fôr publicada a homologação do resultado final, o direito de recurso ao Poder Judiciário contra a legalidade de quaisquer atos relativos a concurso para provimento de cargos em empregos na Administração Direta ou nas Autarquias.

Art. 5' Decorrido o prazo de 3 (três) anos, a contar da data da publicação do ato homologatório do resultado final, e não havendo recurso $s u b$ judice poderão ser incinerados as provas e o material inservivel de cada concurso. 
Art. 6? Compete ao DASP zelar pela integral observância das leis, regulamentos e normas que dispõem sôbre recrutamento e seleção de pessoal para a Administração Direta e para as Autarquias, sendo-lhe assegurada a faculdade de intervir em qualquer fase do processo seletivo.

Art. 7ํ A inobservância das disposições legais, regulamentares e normativas sôbre a matéria de que trata êste decreto-lei, incompatibiliza o dirigente ou titular de chefia mediata ou imediata para o exercício do cargo em comissão, função gratificada ou emprêgo de confiança que ocupar, devendo ser imediatamente exonerado ou dispensado.

Art. 8․ Ficam revogadas a Lei n? 5.091, de 30 de agôsto de 1966, e demais disposições em contrário.

Brasília, 27 de agôsto de 1969; 148 da Independência e 81\% da República. - A. Costa e Silva - Luis Antônio da Gama e Silva - Augusto Hamann Rademaker Grünewald - Aurélio de Lyra Tavares - José de Magalhães Pinto - Antônio Delfim Netto - Mário David Andreazza - Ivo Arzua Pereira - Tarso Dutra - Jarbas G. Passarinho. - Márcio de Souza e Mello - Leonel Miranda - José Fernandes de Luna - Antônio Dias Leite Júnior - Hélio Beltrão - José Costa Cavalcanti - Carlos F. de Simas. 


\section{Palavras de Encerramento Proferidas pelo Professor Glauco Lessa de Abreu e Silva, Diretor-Geral do DASP}

ENHORES Diretores e Chefes de Pessoal; prezados co-
legas.

Ao encerrarmos esta II REUNIÃO, cremos não incorrer em imodéstia ao considerar que o nosso trabalho está coroado de êxito. E não seremos imodestos porque o mérito dêsse sucesso, pelo qual nos congratulamos com os Senhores, não é nosso: é dos colegas, que aqui compareceram, trouxeram suas idéias, suas observações, e, imbuídos do desejo de acertar, deram o melhor de sua colaboração.

É uma demonstração a mais de que estamos - os Senhores e nós - preparados para o exercício pleno, permanente e consciente da nova filosofia, trabalhando juntos para trabalhar melhor.

A Administração necessita, por sua dinâmica, da ação integrada de seus agentes; é o que estamos conseguindo com esta série de encontros. Cada um dos Senhores constitui para nós, do DASP, um manancial de conhecimentos e de experiência que saberemos valorizar e aproveitar para benefício de todos.

Em têrmos de Administração, não somos dos que crêem em verdade absoluta; da soma das verdades de cada um de nós, chegaremos àquela que será a verdade de todos, e ninguém será dono da verdade.

É o que o DASP vai agora fazer, com base nas Recomendações que os Senhores elaboraram.

Esta politica foi a que tivemos a honra de sugerir ao Govêrno que aqui nos colocou, e fizemo-lo por saber que ela se provaria altamente positiva.

Esperamos que o entusiasmo que neste momento habita em nós, habite, igualmente, em cada um dos Senhores, a quem agradecemos em nosso nome, em nome do DASP e em nome do Govêrno, - pela presença, pelo interêsse, pela colaboração, pelas idéias, pela confiança com que atendem ao nosso chamado, na pessoa dos Coordenadores de Comissões:

Prof. Manoel Alves Mendes Júnior

D* Regina Vereza Bruzzi

Dr. Milton de Andrade e Silva

Dr. César Augusto Gasparini Velloso 